\title{
15 Literatur
}

Brauner, H.: Lehrbuch der konstruktiven Geometrie. Wien: Springer, 1986

DIN (Hrsg): Praxishandbuch Technisches Zeichnen. Berlin: Beuth, 2003

DIN (Hrsg): Technisches Zeichnen 1. Grundnormen. DIN-TAB 2/1. 14. Aufl. Berlin: Beuth, 2011

DIN (Hrsg): Technisches Zeichnen 2. Mechanische Technik. DIN-TAB 2/2. 8. Aufl. Berlin: Beuth, 2011

DIN (Hrsg): Längenprüftechnik 1. Grundnormen. 3. Aufl. Berlin: Beuth, 2012

Glaeser, G: Geometrie und ihre Anwendungen in Kunst, Natur und Technik. München: Elsevier, 2005

Grollius, Horst-W.: Technisches Zeichnen für Maschinenbauer. München: Carl Hanser, 2010

Häger, W., Bauermeister, D.: 3D-CAD mit Inventor 2008. Tutorial mit durchgängigem Projektbeispiel, Wiesbaden: Vieweg + Teubner, 2008

Henzold, G.: Form und Lage. Beuth Kommentar. 3. Aufl. Berlin: Beuth, 2011

Henzold, G.: Anwendung der Normen über Form- und Lagetoleranzen in der Praxis. 7. Aufl. DIN-Normenheft 7. Berlin: Beuth, 2011

Hoischen/Fritz: Technisches Zeichnen. Grundlagen, Normen, Beispiele, Darstellende Geometrie. 35. Aufl. Berlin: Cornelsen, 2016

Klein, B.: Toleranzmanagement im Maschinen- und Fahrzeugbau. Form- und Lagetolerierung, Toleranzprinzipien, Tolerierungsverknüpfungen, Maßketten, Oberflächen. München: Oldenbourg, 2006

Kurz, U. et. al.: Konstruieren, Gestalten, Entwerfen. 4. Aufl. Wiesbaden: Vieweg + Teubner, 2009

Jorden, W., Schütte, W.: Form- und Lagetoleranzen. Handbuch für Studium und Praxis. 7. Aufl.

München: Carl Hanser, 2012

Labisch, S., Weber, C.: Technisches Zeichnen. Selbständig lernen und effektiv üben. 4. Aufl. Wiesbaden: SpringerVieweg, 2013

Raich/Rudiferia: Grundlagen der Konstruktionslehre. Troisdorf: Bildungsverlag EINS, 2004

Schließer/Schlindwein/Steinhilper: Konstruieren und Gestalten. Würzburg: Vogel, 1989

Viebahn, U.: Technisches Freihandzeichnen. Berlin: Springer, 1993 